\title{
4 the Role of VAlue COMPATIBILITY IN INFORMATION TECHNOLOGY ADOPTION
}

\author{
Deborah Bunker \\ University of New South Wales \\ Sydney, Australia \\ Karlheinz Kautz \\ Copenhagen Business School \\ Frederiksberg, Denmark \\ Anne Luu Thanh Nguyen \\ University of New South Wales \\ Sydney, Australia
}

\begin{abstract}
Compatibility has been recognized as an important element in the adoption of IT innovations in organizations but as a concept it has been generally limited to technical or functional factors. Compatibility is also significant, however, with regard to value compatibility between the organization and the adopted IT innovation. We propose a framework to determine value compatibility analyzing the organization's and information system's structure, practices, and culture and to explore the value compatibility of an organization with its adopted self-service computer-based information system. A case study was conducted to determine the congruence of an organization's value and IT value compatibility. This study found that while there was a high correspondence in the organizational structure and practices dimensions, there were organizational culture disparities. The cultural disparities reflected the selfservice acceptance and training issues experienced by the case organization. These findings explain the problems experienced with value compatibility and the adoption of the information systems and show the suitability of the framework for the detection of such problems.
\end{abstract}

Keywords Value compatibility, IT innovation

Please use the following format when citing this chapter:

Bunker, Deborah, Kautz, Karlheinz, Thanh Nguyen, Anne Luu, 2006, in International Federation for Information Processing (IFIP), Volume 206, The Transfer and Diffusion of Information Technology for Organizational Resilience, eds. B. Donnellan, Larsen T., Levine L., DeGross J. (Boston:

Springer), pp. 53-70. 


\section{INTRODUCTION}

The idea that innovations may be compatible or incompatible with an organization's existing (information) systems or resources has been long advocated in the innovation literature by, for example, Rogers (1995), whose definition of compatibility highlights the traditional view of the concept:

compatibility is the degree to which an innovation is perceived as consistent with the existing values, past experiences, and needs of potential adopters. An innovation can be compatible or incompatible: with socio-cultural values and beliefs, with previously introduced ideas, or with clients needs for innovations (p. 224).

The incompatibility of the potential adopters' cultural values with the innovation will hinder the adoption process and there is the belief that the higher the compatibility of an idea, the lower the uncertainty felt by the potential adopters (Rogers 1995). Among those who have researched organizational values and have found that they influence the successful adoption of IT innovations are Orlikowski (1993) and Zammuto and O'Connor (1992).

The traditional view of compatibility has, however, been criticized by Tornatsky and Klein (1982) as being too broad. In their meta-analysis of innovation adoption and implementation, they argue that it is more appropriate to distinguish between value compatibility and practical compatibility. Value compatibility refers to the suitability of the innovation with the norms or values of the potential adopters. Practical compatibility refers to the suitability of the innovation with the current practices of the adopters. Klein and Sorra (1996) reinforce this view in their model of innovation implementation success. Their proposed model explains that successful innovation implementation is due to both the formal mechanisms creating a climate for the innovation's implementation, which can be understood as practical compatibility, and value compatibility, which they define as the fit of an innovation to the targeted users' values at the organizational and group levels. Harrington and Ruppel (1999) also acknowledge the dual nature of compatibility. They motivate their work by relating to Cooper (1994), who suggests that organizational culture and its associated values comprise an area that has largely been ignored by IT implementation researchers. Supported by Romm et al. (1991), they make the argument that without a match between the values of an organization and the value assumptions embedded in an IT innovation, a costly implementation failure is likely to occur.

This argument is central to this paper and we try to fill this gap by providing a study of value compatibility between an organization and a computer-based information system and its influence on the adoption of the information system. For this purpose we develop a research framework, which emphasizes organizational structure, practices, and culture and their embeddedness in an information system and application to a specific case.

In the remainder of the paper we present our framework, our research method, and our case organization as well as the information system. We then describe and discuss our findings and finish with some conclusions. 


\section{A FRAMEWORK TO STUDY VALUE COMPATIBILITY}

Organizational values are a defining part of organizational culture (Schein 1984). According to Robbins and Langton (2001), researchers in the field agree that the following seven dimensions jointly explain organizational culture: innovation and risktaking; attention to detail; outcome orientation; people orientation; team orientation; aggressiveness; and stability. The dimensions describe the degree to which employees are encouraged and expected to act in certain ways, the level of management focus on outcomes and people, the way employees interact with each other and externally, as well as the level of drive of the company to maintain the status quo or to change with the times (Robbins and Langton 2001). These seven dimensions form the first part of our framework.

While values are the invisible manifestations of organizational culture, organizational practices are their visible counterpart. Therefore, organizational practices have to be taken into account when studying organizational values and culture. Hofstede (1994), beyond heroes and symbols, considers rituals as important expressions of practices and he distinguishes six dimensions, which are helpful for their detailed investigation: process-orientated versus results-orientated; employee-orientated versus job-orientated; parochial versus professional; open systems versus closed systems; loose control versus tight control; and normative versus pragmatic organizations. While the first two dimensions are rather self-explanatory, the others require some elaboration. The parochial versus professional dimension refers to the level to which the employee's identity is derived from the organization as opposed to deriving their identity from the type of job they hold. Furthermore, parochial companies may take into consideration social and familial background as much as the job competence in the hiring process. In contrast, professional organizations hire solely on the basis of job competence and employees' private details are not considered. Open systems versus closed systems may be referred to as the communication climate of the company. The image of welcoming organizations where employees feel part of the team may be contrasted with a very secretive organization where only special people will feel accepted. Loose versus tight control refers to the restraint or checks with regard to budgets, meeting times, and level of formalness. Finally, normative versus pragmatic practices deal with the notion of customer orientation. Pragmatic organizations are market driven as opposed to normative organizations, which place high importance in following organizational procedures and ensuring that the ethical standards and honesty are upheld. The image of a private sector organization as opposed to a government organization may be helpful in understanding this practice dimension (Hofstede 1994). The dimensions form the second part of our framework.

Organizational culture and its values, however, also become visible in organizational structures (Mintzberg 1989), which we take into account when studying compatibility between the organization and its computer-based information systems. Again following Robbins and Langton (2001), the key elements that need to be addressed in the design of an organization's structure include: work specialization; departmentalization; chain of command; span of control; centralization and decentralization; and formalization. Work specialization may also be called the division of labor. Robbins and Langton refer to "the degree [with] which tasks in the organization are subdivided 


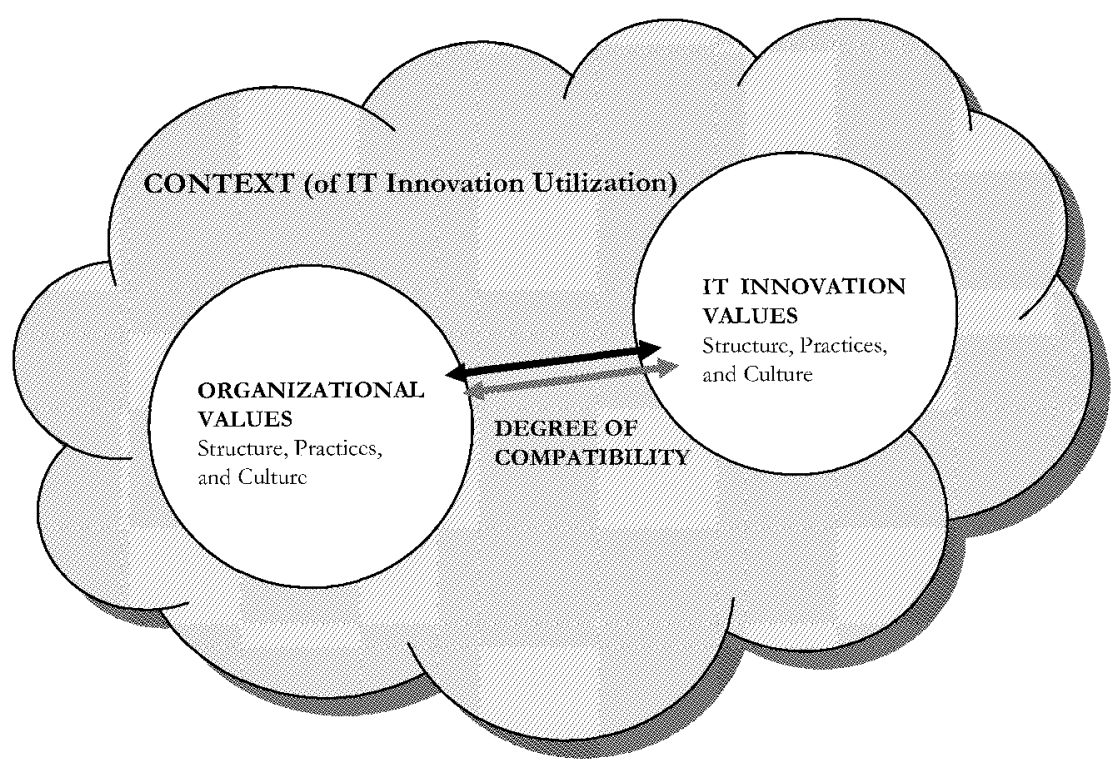

Figure 1. Value Compatibility in IT Adoption

into separate jobs." Departmentalization is the "basis on which jobs are grouped together." Typical forms of departmentalization include, by function, type of product, geography, process and type of customer. The chain of command refers to the "unbroken line of authority that extends from the top of the organization to the lowest echelon and clarifies who reports to whom." The span of control refers to "the number of employees which a manager can effectively and efficiently direct." Centralization refers to the "degree to which decision making is concentrated at a single point in the organization." On the other hand, decentralization occurs when the "decision discretion is pushed down to lower-level employees." Finally, formalization refers to the level in which "jobs within the organization are standardized."

In summary, our framework (see Figure 1) to study value compatibility between information systems and organizations consists of three dimensions. The context for which IT innovations are utilized is entrenched in the organizational values, which are reflected in the structure, practices, and culture of an organization. In the following, we will illustrate the suitability of our framework and the importance of value compatibility through the analysis of a particular case.

\section{THE RESEARCH METHOD}

As the research aims at exploring the value compatibility of an organization with a computer-based information system in terms of its structure, practices, and culture, an interpretive, qualitative case study is, in this instance, more appropriate to study these dimensions than undertaking a positivist quantitative study. The descriptive complexities of organizational structure, practices, and culture mean that a qualitative 
approach can better cater to describing nuances as well as exploring information that would otherwise not be possible if restricted to certain quantitative criteria. This is especially important as our work aimed to also discover organizational issues that may have hindered the adoption of the system by the members of the organization. Myers (1997) categorizes qualitative research into the underlying epistemology that influences and guides the research: positivist, interpretive and critical. Although organizational issues have become a major focus for information system researchers in recent years, "much of this literature reflects a rational-economic interpretation of organizational processes, and a positivist methodology which is based on the view that the world exhibits an objective cause-effect relationship which can be discovered, at least partially, by structured observation" (Walsham 1993, p. 4). While these methods are powerful, other researchers have highlighted some inherent limitations of a positivist approach, which are summed up by Kraemer and King (1990) as the inability to "explain the variance observed in the patterns and processes of adoption and routinization of information technology in various tasks" and "the differences in successful use of the technology across organizations" (p. 583). Other information system researchers have advocated the interpretive epistemology of research as it

can help information system researchers to understand human thought and action in social and organizational contexts; it has the potential to produce deep insights into information systems phenomena including the management of information systems and information systems development (Klein and Myers 1999, p. 67).

The interpretive epistemology aims "at producing an understanding of the context of the information system, and the process whereby the information system influences and is influenced by its context" (Walsham 1993, pp. 4-5). Hence, the interpretive epistemology is very apt for our research as the context in which the information system is utilized is significant for the exploration of value compatibility between the adopting organization and the information system. In the interpretive tradition, theories are neither correct nor incorrect. These theories are compared, evaluated, and improved upon with the aim of creating "intersubjectively tested theoretical approaches, considered of value to a broader group than a single individual" (Walsham 1993, p. 6).

The research itself was conducted as a case study that utilized 12 semi-structured, open-ended interviews with 3 systems administrators and 9 system users from 5 different departments, as well as observations and analysis of artefacts such as employee newsletters, employee manuals, company posters and ornaments, systems development documents, training manuals, employee advertisements, and signage in the exploration of the context.

\section{THE CASE}

The case organization is a beverage company, which manufactures, sells and distributes a wide range of nonalcoholic ready-to-drink beverages. In the Asia Pacific region, it is the largest bottler, spanning six countries. The Beverage Company's (TBC) flagship licensed drink is also the market leader in the leisure industry. Marketing for the 
drink is high, often associated with youthful, fun, and jovial images. TBC's presence in Australia began in the early 1900 s and since then has undergone many acquisitions and mergers. Today it is a public company and employs approximately 3,500 people.

The business owner of the system under investigation is the Accounts Payable department. The Non-Inventory Purchasing System (NIPS) is a PC-based e-commerce information system for the procurement of TBC's non-inventory items in Australia. Non-inventory goods are items that are not direct inputs into the production of the beverages produced by the company. NIPS is a web-based purchasing software package and is the only mechanism for obtaining non-inventory goods at TBC. As part of the system implementation, the Accounts Payable department was centralized nationally. The purchasing job functions of the administrative employees, for example executive assistants and purchasing officers, were transferred to the employee population for selfservice and self-maintenance.

NIPS contains on-line catalogs that assist the approximately 2,500 system users in making electronic requests. For strategic items, there is a fully integrated approval process. Corporate purchasing cards, of which approximately 1,700 are issued, are usually of low value and are used in conjunction with the system for nonstrategic items. The purchasing card is similar to a credit card with limits imposed. The system also provides functionality to manage the corporate purchasing cards. Limits on the cards are hierarchically allocated based on the employee's position as well as their specific needs. The system allows employees to verify purchases made with their purchasing card. A database of all non-inventory purchases provides information on purchasing patterns and can assist the company in its supplier negotiations. In parallel with business rules, features such as automatic routing to approvers, automatic creation of purchase orders, and dispatch to the vendors (via the nominated method, including e-mail), eliminates clumsy communication channels and also the need for purchase officers. The benefits, which were presented by the NIPS business case, included empowering employees and enabling them to get on with the job; savings as a direct result of reduced headcount; lower time and effort required by the business to make a purchase; enforced time control for approvals to be made; ability to enforce the standards of products; ability to obtain the whole picture of purchasing patterns; and data to assist in the negotiation of supplier agreements. The system owners, however, were dissatisfied with the adoption and use of the system and a commissioned pilot study highlighted problems and showed that the expected benefits were not realized.

\section{CASE STUDY FINDINGS}

Our framework for analyzing value compatibility as a prerequisite for IT adoption emphasizes the concepts of organizational structure, practices, and culture and their embeddedness in information technology artefacts and information systems. Applying these concepts, our findings are next outlined with regard to the value compatibility of TBC and the NIPS (the information system) that the organization had implemented to support its purchasing processes. 


\subsection{TBC Structure and Value Compatibility with NIPS}

\subsubsection{TBC Structure}

Work specialization is relatively high at $\mathrm{TBC}$; however, the jobs are not unfulfilling and meaningless. For example, within the Accounting department, the accounting concerns of the company are subdivided into accounts payable, payroll, operations accounting, revenue accounting, etc. Within each functional department the roles are specialized to the skill-level required and a Projects Portfolio Team documents the skills, knowledge of technologies, experience, and basic level of competency required for the team members.

TBC is organized in eight departments-Finance, Operations and Logistics, Employee Relations, Corporate Affairs, Strategic Programs, Sales and Customer Service-Field Operations, Sales and Customer Service-National Business, and Information Systems - thus there is high departmentalization and within departments there are further groupings by state, type of customer, type of product, and type of process. For example, within Employee Relations, the function has regional departmentalization by states and also by the functional speciality such as operations and logistics, commercial, business support services, and learning and development on a national level. Within the National Business department, there are two subdepartments.

Departmentalization has led to a chain of command that is fairly clear, especially in the traditional operations and accounting departments, whereas the introduction of cross-functional teams resulted, for example, in multiple reporting paths and wide access to information through technology. This has made the employees less reliant on their immediate managers for information.

The span of control at TBC differs with many functions revolving around teamwork. By using team leaders as intermediaries, managers can also manage a greater number of employees. Therefore, there is no standard number of employees for a span of control.

On the whole, TBC is mostly centralized with the majority of the business support activities operating out of the head office and one plant site. Departments such as Employee Relations that require physical presence in the state regions are more decentralized with groupware technologies such as Lotus Notes allowing control at the head office to be preserved. It is highly evident that the decision discretion for items such as marketing, information system projects, and financial analysis is planned and conducted in the head office and subsequently executed elsewhere. The production of beverages, on the other hand, is the responsibility of individual states.

Manufacturing, accounting and customer services are fairly standardized and formalized, while more creative activities such as planning for and marketing are less standardized, allowing employees to use their own judgement. Standardization occurs not just within the company premises but also throughout the areas in which TBC supplies its products. In supermarkets and smaller outlets, the shelf location and placement of the drinks follow a specific pattern to increase sales.

In summary, $\mathrm{TBC}$ is a combination of a bureaucracy, a matrix, and team structure. The bureaucratic nature of TBC is very evident in the ways in which protocols such as issues escalation are adhered to. Furthermore, there is the perception that the "buck 
stops with senior executives." The matrix is often seen in project-related work, whereas the team structure is present in most departments. In this environment, TBC utilizes information technology heavily in many facets of work.

\subsubsection{NIPS Structure}

NIPS has been designed for nonspecialists to perform procurement activities, which in the past has been an accounting domain. In terms of work specialization, although it is a system for a specific purpose, it can be characterized as exhibiting low specialization.

Departmentalization is evident in the types of financial approvals given to the purchase requests. Financial approvals may be by project, category, or cost center with different approval procedures. For each category or cost center, the approvers only see and approve the items to which they are assigned.

The chain of command is an important concept of the information system and its operation. On the simplest level, there are four user access levels. All users of NIPS can raise a request; however, the difference in user access levels determines their ability to make approvals, view requests from others, view all details in the system, create specific reports, add users, alter details, suspend cards, and conduct other system administration activities. The systems administrator has the highest access level and is able to perform most of the activities. The approval process also reflects the chain of command. Approvals may be associated with a user or position and the methods used may be sequential, direct, hierarchical, or group. An approval of a request will be sent to the manager of the requester and then on to the next person in the chain of command until approval is reached. Within this type of approval there are two choices: sequential or direct. In any case, the chain of command is clearly defined through the systems.

Span of control is another fundamental concept in NIPS. Each employee has a credit limit for what they can purchase. These values are determined on an as-needed basis, not solely depending on the employee level. A manager in one department may have a different credit limit than a manager on the same level in another department. Managers also have a limit on the amount to which they may make approvals and again different procedures are used depending on the different but clearly defined range of mandates that are implemented.

The structure of the system is both centralized and decentralized. Thus, although being rather bureaucratic, NIPS allows the accounts personnel at the head office to stay in control and to centrally maintain the administration of the system and purchases. Thus, the systems administrator residing at the head office is, for example, responsible for issuing and suspending purchase cards for all the states. The decentralization allows individuals to maintain and administer purchases themselves rather than relying on an accounts payable officer. Furthermore, a state-based purchasing administrator provides assistance for each state.

Finally, another significant component of the system is the formalization of rules and system procedures to ensure control and that correct actions take place. When employees want to make a purchase, they must follow the defined five step process. Skipping one phase, namely confirming the receipt of the goods, before creating an invoice as practiced by many employees is not tolerated by the system. A key respon- 
Table 1. Organizational Structure of TBC and as Embedded in NIPS

\begin{tabular}{|l|l|l|}
\hline \multicolumn{1}{|c|}{$\begin{array}{c}\text { Structural } \\
\text { Dimension }\end{array}$} & \multicolumn{1}{|c|}{ The Beverage Company } & \multicolumn{1}{c|}{ NIPS } \\
\hline Work Specialization & High & Low \\
\hline Departmentalization & High & High \\
\hline Chain of Command & Clear & Clear \\
\hline Span of Control & Varying & Varying \\
\hline $\begin{array}{l}\text { Centralization/ } \\
\text { Decentralization }\end{array}$ & $\begin{array}{l}\text { Centralization of support } \\
\text { activities at head office } \\
\text { Decentralization of infor- } \\
\text { mation dissemination and } \\
\text { manufacturing of products }\end{array}$ & $\begin{array}{l}\text { Centralization of } \\
\text { administrative functions } \\
\text { Decentralization of usage } \\
\text { (self-service procurement) }\end{array}$ \\
\hline Formalization & High & High \\
\hline
\end{tabular}

sibility of the systems administrators is thus to educate users so that the rules are properly followed. Table 1 presents a summary of the structural dimension of value compatibility between TBC and the NIPS.

\subsection{TBC Practices and Value Compatibility with NIPS}

\subsubsection{TBC Practices}

The employees perceive that the company focuses heavily on clear, quantifiable practices, with process also being an important factor. An employee summed up the driving force in the work that they do as objective driven. In different departments, the objective may differ, but the employees focus on, and work toward, achieving that objective. For example, in Sales, the objective is to increase profit and volume. The primary objective of the Information Systems department is to deliver outcomes within the deadlines agreed to and to meet expectations. In both departments, although there is high focus on achieving results, the processes used to ensure the quality of results are significant. Thus, the Project Portfolio Team in the Information Systems department must follow a project life cycle methodology to ensure the completeness of the systems they implement and also to minimize risks and problems.

TBC shows concern and trust for its employees and in return employees are highly dedicated in their work. Within the business support departments, the work hours are flexible, allowing employee discretion and trust that they complete their work. There is no set time or duration for lunch. When there are high workloads, the employees are expected to work harder and have shorter breaks; during quiet times, the employees may have longer breaks within reason. TBC provides on-site food services at subsidized rates. On every floor of the buildings, employees are provided with drinks, coffee, and fruit. Social activities are organized to encourage employee morale and camaraderie. 
Putting these benefits aside, employees are aware of their job role and accountabilities. They like to "get on with the job" and are highly dedicated. In summary, TBC puts equal emphasis on the employees and on their jobs.

When identifying themselves, the employees are proud to be associated with the company values more than those of their profession. When asked what they do, they initially reveal the company and then what they do there. Many employees are often seen wearing clothes displaying the company logo. The high pride in the company is further fostered and encouraged subtly through the many posters displaying the company's flagship drink in history. The parochial attitude becomes more obvious with the number of years an employee has spent with the organization. TBC experiences low turnover and many employees have spent in excess of 5 years at the company; it is not surprising that they tend to identify with the company rather than their profession. It must be noted, however, that within the company, the employees identify and distinguish themselves via the department in which they work or their job role. Moreover, although employees derive their identity from the organization, the recruitment practices of the company are professional. The company hires based on job competence and whether the individual shares the same values as the company. It does not take into account any social or familial factors. On the whole, though, parochial values prevail over professional ones.

When new employees join the company, they are warmly welcomed. The communication climate is generally one of openness and there is the sentiment that everyone can make a difference and is important in the company's success. During recruitment interviews, employee relations officers are concerned if the employee will fit in with the values and culture of the company; however, once someone joins $\mathrm{TBC}$, the atmosphere is one of high acceptance rather than one where only very special people will fit in. The company celebrates the diversity of its employees. Furthermore, employees of all levels are highly approachable and on a first-name basis. Yet sensitive information is kept to management, which indicates, at least with respect to information flow, a partly closed system is in place.

With regard to control, TBC has established the necessary limitations to ensure that physical and intellectual security is maintained and unnecessary costs and time wastage are minimized, thus ensuring efficient functioning of systems. There is tight control over access to the company's work areas; security personnel are responsible for inspecting and allowing access to visitors. Employees are subjected to controls such as Internet usage, software access, database access, and credit limit for purchase cards on a needs-only basis.

Managers must authorize documents and provide reasons for the need. These strict controls are contrasted with the employees' attitude and flexibility of working hours as described earlier and their approach to scheduled meetings where meeting times are only kept approximately. No formal and stern work environment is enforced, informal conversations between colleagues are audible, and employees are free to decorate their personal work spaces. Furthermore, employees have the opportunity to dress "smart casual" rather than in strictly business attire. This reflects a comfortable workplace where the employees balance tight cost and procedural controls with fun and flexibility of their work spaces.

TBC employee newsletters and magazines often celebrate employees and initiatives that improve customer satisfaction. A challenge of the business is to meet the evolving 
needs of their customers and consumers. In the manufacturing function, this is translated to increasing their efficiency. TBC launched a "Changeover Challenge," aimed to "question [ing] the current production processes andmindsets, and encouraged employees to find better ways of changing lines over from one flavor or package to another, and to share that information between operations." Although the ultimate goal is to meet the needs of customers, the employees also have to ensure that quality and safety are not compromised in the new processes. Hence procedures and standardscompliance are important facets of the company. In business support services, policies are also important in their day-to-day jobs. For example, the computer usage policy is strictly enforced and usage will not be tolerated if it does not fall within policy guidelines. Theses policies ensure the security of the company systems and protect their intellectual property. Therefore, the compliance of procedures and standards must be met in the quest and response to customer and market request and forces. In conclusion, normative and pragmatic practices are equally followed.

\subsubsection{NIPS Practices}

NIPS successful function requires a strict adherence to the rules for raising a purchase request through to the invoicing of the order, and therefore the information system shows a high process-orientated nature. With regard to the business benefits, it was supposed to be a symbol for accuracy and for achieving better procurement results. To achieve this, there was a need to streamline the procurement process. The processes imperative for correct utilization of the system are highly documented and easily accessed by users through TBC's intranet. Although giving the employees the responsibility for their purchases, NIPS is completely orientated toward their jobs and noticeably exhibits a professional image.

NIPS is a highly open system in the sense that all employees can use it. However, this openness is not a universal concept. All users have a password and can only view their procurement activities and any approvals that they are required to make. Hence visibility of procurement activities is closed to the individuals' activities, the activity of inferiors, and administrator-level access.

In conjunction with the rules of the system, there are tight controls that ensure the compliance of users and effective operation of the system. The employees are responsible for submitting their purchase card statements by the end of the month. If this is not undertaken, they will have their card suspended until the statement is submitted. There is a mechanism for explaining any difference between the quoted cost of the purchase and what was actually charged and the employees are required to enter the reason for any discrepancy. A formalized interface ensures conformity of any input of purchase data.

Finally, the strict request for process rules and standards compliance shows the normative design of NIPS. Table 2 presents a summary of the practice dimension of value compatibility between TBC and the NIPS. 
Table 2. Organizational Practices at TBC and as Embedded in NIPS

\begin{tabular}{|l|l|l|}
\hline Practice Dimension & The Beverage Company & \multicolumn{1}{c|}{ NIPS } \\
\hline $\begin{array}{l}\text { Process- versus } \\
\text { Results-orientation }\end{array}$ & $\begin{array}{l}\text { Mainly results-orientated, } \\
\text { Less process-orientated }\end{array}$ & Process-orientated \\
\hline $\begin{array}{l}\text { Employee versus } \\
\text { Job orientation }\end{array}$ & $\begin{array}{l}\text { Equally employee- and } \\
\text { Job-orientated }\end{array}$ & Job-orientated \\
\hline $\begin{array}{l}\text { Parochial versus } \\
\text { Professional }\end{array}$ & $\begin{array}{l}\text { Mainly parochial, } \\
\text { Still professional }\end{array}$ & Professional \\
\hline $\begin{array}{l}\text { Open Systems versus } \\
\text { Closed Systems }\end{array}$ & $\begin{array}{l}\text { Generally openness } \\
\text { Partly closed system with } \\
\text { regard to sensitive } \\
\text { information kept to } \\
\text { management }\end{array}$ & $\begin{array}{l}\text { General open for all to use. } \\
\text { Closed system through } \\
\text { password security and } \\
\text { limited access to purchase } \\
\text { and approval data }\end{array}$ \\
\hline $\begin{array}{l}\text { Loose Control versus } \\
\text { Tight Control }\end{array}$ & $\begin{array}{l}\text { Cost: Tight } \\
\text { Time: Low Punctuality } \\
\text { Language and } \\
\text { Dress: Informal }\end{array}$ & $\begin{array}{l}\text { Cost: Tight } \\
\text { Time: High Punctuality } \\
\text { Language: Formal }\end{array}$ \\
\hline $\begin{array}{l}\text { Normative versus } \\
\text { Pragmatic Practices }\end{array}$ & $\begin{array}{l}\text { Equally normative and } \\
\text { pragmatic }\end{array}$ & Normative \\
\hline
\end{tabular}

\subsection{TBC Culture and Value Compatibility with NIPS}

\subsubsection{TBC Culture}

TBC sees itself as being responsive to the changing needs of its customers and consumers. It tries to be innovative to some extent, but it also acknowledges that it is the market leader and does not feel the need to be extremely innovative and to take unnecessary risks. Innovativeness is often geared toward marketing. For example, the company was the first to implement vending machines that can dispatch a can of drink using a mobile phone. Within the company, TBC also tries to be innovative to keep up with the changing times. In total, TBC prefers to take calculated and educated risks. Many months of planning and risk management procedures are conducted prior to the start of projects, new product developments, and acquisitions of other companies.

The level of attention to detail is set by the managers of the departments and an employee described it as a "as we need to" basis. This is reemphasized when it is felt that "we are out of control." The level of attention to detail differs between departments; the Finance and Accounting departments are more accurate than the Information System department. When making major decisions, such as selecting a vendor, the employees try to minimize risks and are expected to fully document the decision, providing objective data to support their recommendation.

$\mathrm{TBC}$ has a strong emphasis on outcome and the quality of the outcome. However, the processes and techniques used to achieve these outcomes must comply with policies and principles, such as safety and quality standards in the production of the drinks. 
Furthermore, the type of outcome or objective depends on the department; for example, Sales people are highly focused on selling drinks and thus on achieving volume and profit whereas the Finance department is focused on ensuring that reports are completed within deadlines.

While TBC is concerned with high productivity, it also believes that this comes through treating its people in the proper manner. There are many benefits and facilities that aim to make the workplace comfortable for employees. The level of concern at $\mathrm{TBC}$ for its employees and the level at which employees are valued appear to be higher than other organizations as shown by the loyalty of its employees. However, it also has to be stated that when decisions are made, people are not always the primary concern and while there is concern for people, the level of thought on the implications to employees is often not fully considered. For example in information systems implementations, technological approaches generally dominate with the level of concern for employees being restricted to the issue of systems training.

Work teams are enforced on every level of TBC. They enable high interaction between the team members and team meetings are usually held on a weekly basis.

The relationship of employees, by and large, is easy-going and everyone is willing to lend a hand. However, politics and aggressiveness occur especially in the event of crises, where political battles are waged so as to avoid blame.

Finally, TBC has been a reputable and stable organization with a long tradition and history and its employees are not very comfortable with widespread and extreme change. This is not in contradiction to organizational activities that emphasize growth and the quest to continually improve, as the employees largely accept a certain level of uneasiness and uncertainty, and they support the notion that to survive and improve productivity, TBC needs to be dynamic and continually evolving.

\subsubsection{NIPS Culture}

With regard to innovation and risk taking, the NIPS certainly represents enormous innovation and a high risk, as it was one of the first e-procurement systems to be implemented in Australia. The system exploits the capabilities provided by Internet browsers and networking. The embedded online training reflects the digital age as it, in a sense, replaces face-to-face training with interface-to-face training.

The attention to detail, and in this case cost details, is very high as NIPS emphasizes the need for accuracy in selecting account codes and prices for articles purchased. Although there is high attention to detail expected of the users, the prices listed on the system are only indicative as some products such as computing goods have frequent price fluctuations and it is difficult to update the cost tables accordingly in a timely manner. Reasons must be provided, however, for discrepancies in expected purchase prices and what was actually paid.

With regard to the outcome dimension, it can be stated the NIPS is a system that relies heavily on processes to obtain the final result. It is vital that the employees complete all components of the process; otherwise the system will not function accurately. Thus, the NIPS has a strong emphasis on process, although aiming at a correct and efficient purchase as an outcome, so the outcome orientation has to be considered as low. 
The people orientation of NIPS rests on its promotion as a self-service system that empowers users. Although this is marketed as a benefit, it has both positive and negative consequences. Employees can now get on with the procurement job without relying on another person. However, this assumes that employees have the competence to use the system. This assumption, however, provides space for errors. The low orientation toward people is also mirrored in the online training, aimed at minimizing face-to-face interaction. The human-computer interaction features of NIPS show a low concern for users and there are no means for obtaining and judging what are effective skills. Despite providing some help facilities, the low intuitiveness of NIPS reflects little consideration of nonspecialist users. This all contributes to an overall low people-orientation.

NIPS is very much orientated toward individuals rather than being team focused. The individual employees are responsible for their purchases and the approvals for their chain of command.

The aggressiveness of NIPS lies mainly in the actions of the systems administrator when employees show little regard for submitting their purchase card statements on time or abuse features of the system. In order to ensure proper usage of the system, the systems administrator must use tactics such as suspension of purchase cards to force compliance.

Finally, NIPS is not considered by employees to be a stable system, with down times and a lack of accessibility occurring regularly. Table 3 presents a summary of the cultural dimension of value compatibility between TBC and the NIPS.

\section{DISCUSSION}

The comparison of TBC and NIPS along the structural, practice, and cultural dimensions shows that the highest correspondence is between the structure of the organization and the structure of the information system. This is, however, not that astonishing as the structure of the organization, with its levels of authorization and its spans of control, was

Table 3. Organizational Culture of TBC as Embedded in NIPS

\begin{tabular}{|l|l|l|}
\hline Cultural Dimension & \multicolumn{1}{|c|}{$\begin{array}{c}\text { The Beverage } \\
\text { Company }\end{array}$} & \multicolumn{1}{c|}{ NIPS } \\
\hline $\begin{array}{l}\text { Innovation and Risk- } \\
\text { Taking }\end{array}$ & $\begin{array}{l}\text { Low innovativeness and } \\
\text { Calculated risk taking }\end{array}$ & $\begin{array}{l}\text { Highly innovative-one of the } \\
\text { first e-procurement systems } \\
\text { implemented in Australia }\end{array}$ \\
\hline Attention To Detail & $\begin{array}{l}\text { Medium in general } \\
\text { High in specific area }\end{array}$ & High \\
\hline Outcome Orientation & High & Low \\
\hline People Orientation & $\begin{array}{l}\text { High in general } \\
\text { Medium to low in } \\
\text { specific areas }\end{array}$ & Low \\
\hline Team Orientation & High & Low \\
\hline Aggressiveness & Low & Low \\
\hline Stability & High & Low \\
\hline
\end{tabular}


apparently the basis for the system. Yet, the company and information system differ with regard to the work specialization dimension. While the work of employees is generally specialized, the information system requires everyone to perform an activity, namely procurement (which was formerly performed by the accounting domain), for which they are not specialists.

Like many other computer-based information systems, NIPS has been constructed around the formal aspects of organizational structure, which the company exhibits. These reveal the underlying economic ambition and control of the corporation. With regard to practices, on each of the scales, the information system displays partial similarities with the practices of the organization. The regimented aspects, in which the system resembles the organization most, are job-orientation, with its orientation toward normative practices and cost control. To a lesser extent as opposed to the information system, the organization also displays process-orientation and an orientation towards professionalism. These elements are in line with the bureaucratic character of the organization's structure. With regard to control, however, the system exceeds the organization by implementing strict time control and a more formal form of interaction.

The organizational culture shows the least congruence between TBC and the information system. Organizational culture as the invisible force behind the tangibles and observables in any organization is the most difficult of the three to capture. Therefore, an externally produced information system is generally hard to align with the culture of an organization.

TBC and NIPS correspond with low aggressiveness. For the attention to detail, they partially correspond. However, in other areas there are major contrasts. Where the company takes very calculated risks and has low innovativeness, for TBC NIPS is quite an innovation; where the company values outcome, NIPS is rather process-orientated; where the company is built upon a high people orientation, the information system exhibits a low concern with human aspects; where the company emphasizes teams, the information system stresses individuals, and where TBC appears to be a stable organization, NIPS shows evidence of instability due to numerous technical problems.

In particular, the difference with regard to people orientation deserves more detailed consideration. It becomes apparent in two major issues, namely self-service and online training.

Self-service is an integral part of the promotion and operation of the system. The shift away from reliance on accounting personnel toward an inclusion of purchasing activities into everyone's day-to-day responsibilities has been one of the main challenges and a source of dissatisfaction among the employees. While self-service has been accepted by some groups of employees, others have not accepted it. The amount of time spent on the system by executives and sales personnel does not correspond to the benefits that NIPS provides to the company. Thus, the savings expected by self-service and the anticipated reductions of staff were not achieved. The eliminated purchasing officers were replaced with personal administrators or even dedicated purchase administrators for each department. Instead of being self-service, it has become peer-service, as the employees would identify a person who was the expert in the use of the system in their work area and nominate that person to conduct the purchasing activities. When they did have to use the system, they would request their colleague's assistance. Some departments have also felt the need to formally hire dedicated personnel to deal with the new procurement or added it to the workload of the existing personal assistants. 
There was the assumption that self-service would be welcomed and accepted by all employees. Instead it resulted in unintended system usage and new requirements for the hiring of new personnel. Hence, the self-service has only been accepted to a limited extent and has hindered the effective adoption of the system.

The self-service concept, however, is not limited to the usage of the system, but extends to the online training for the system. This too was a major problem, showing lack of genuine concern for the employees' ability to use the system, further encumbered the effective adoption process. Our interviews indicated that there is quite an effort involved to confidently use the system. Only a small number of dedicated key users got the opportunity to practice system use and had access to the necessary support during the initial pilot stages of the system implementation, which enabled them to grasp the complexities of the system. The training software was difficult to understand in itself (let alone the actual NIPS). Training for the system was often put-off by the employees, as many perceived that performing their work had higher priority than taking the time to complete the training. Even those who completed the training, however, reported that it did not provide a "feel" for what the information system was about. The training consisted largely of the employees sitting in front the computer and clicking buttons for the length of the session. The frustrations generated through the lack of understanding of the NIPS resulted in an increased negative perception of the system, affected its acceptance, and lead to only limited adoption.

In summary, we found a certain value compatibility mostly with regard to structure, less so with regard to practices, and least so with respect to culture. The lack of congruence with culture has caused considerable dissatisfaction. Depending on the nature and level of discontent, some employees have voiced their disgruntlement, but have shown hopefulness and loyalty, while others have become indifferent, neglected the system, and avoided using it. The avoidance of the system has been the most common reaction with the consequences described above. However, no one has left the company because of the system. Perhaps the extent of the compatibility is sufficient to prevent open resistance and rejection and accounts for why the dissatisfied employees only project tame or passive expressions of discontent and tolerate the system. However, alleviation of the disparities might ensure a better fit between $\mathrm{TBC}$ and the information system and subsequently more effective adoption of the system with better results for the company.

\section{CONCLUSIONS}

While there have been many studies on the compatibility of innovations, there has been little research specifically focused on the area of value compatibility of IT innovation. There are issues beyond value compatibility that influence adoption of IT innovations in organizations, but value compatibility is essential for the adoption of IT innovations. Value compatibility assessments provide insights to key areas and issues that are necessary for the successful adoption of IT innovations. This research provides one way of analyzing the value compatibility of organizations and computer-based information systems. The investigated case (TBC) has highlighted areas of disparities that had an influence on the effective adoption of the IT innovation. The concept of value 
compatibility was studied in the context of packaged standard systems (NIPS), independent of taking into account who built the system and the underlying development process. Future studies should also take these aspects into account.

The research found that the structural and practices dimensions of the organization and system had a higher fit than the cultural dimensions. The major issues were related to the self-service aspect of the system and the method of training. The ways in which the users have responded to these issues show that while they were dissatisfied, they were still able to tolerate the information system as there was some value compatibility between the organization and the information system.

The study has shed light on the practice of IT innovation adoption. There have been 30 years of research on the impact of information technology on organizations and the need for contextual analysis. Although there have been many successful IT innovations, the high failure rate of IT innovations continues to haunt the field. It is, therefore, necessary to ask why organizations are still underestimating the effects of organizational values on the success of the information system adoption. In a world dominated by rational, economical, and technology deterministic views, much education of organizational and social theories at the grassroots level of the practitioners' career paths may help to sway the tide to embrace organizational issues.

\section{References}

Cooper, R. "The Inertial Impact of Culture on IT Implementation," Information and Management (27), 1994, pp. 17-31.

Harrington, S .J., and Ruppel, C. P. "Practical and Value Compatibility: Their Roles in the Adoption, Diffusion, and Success of Telecommuting," in P. De and J. I. DeGross (eds.), Proceedings of the $20^{\text {h }}$ International Conference on Information Systems, Charlotte, NC, 1999, pp. 103-112.

Hofstede, G. Cultures and Organizations: Software of the Mind, London: Harper Collins Business, 1994.

Klein, H. K., and Myers, M. D. "A Set of Principles for Conducting and Evaluating Interpretive Field Studies in Information Systems," MIS Quarterly (23:1), 1999, pp. 67-94.

Klein, K. J., and Sorra, J. S. "The Challenge of Innovation Implementation," Academy of Management Review (21:4), 1996, pp. 1055-1080.

Kraemer, K. L., and King, J. L. "Social Analysis in MIS: The Irvine School, 1970-1990," in J. F. Nunamaker (ed.), Proceedings of the $27^{\text {th }}$ Hawaii International Conference on System Sciences, Los Alamitos, CA: IEEE Computer Society Press, 1990, Volume 3, pp. 582-590.

Mintzberg, H. Mintzberg on Management: Inside Our Strange World of Organizations, New York: The Free Press, 1989.

Myers, M. D. “Qualitative Research in Information Systems," MISQ Discovery, archival version, June 1997 (available online at http:/www.misq.org/discovery/MISQD_isworld/index.html).

Orlikowski, W. "Learning from Notes: Organizational Issues in Groupware Implementation," The Information Society (9:3), 1993, pp. 237-250.

Robbins, S. P., and Langton, N. Organizational Behavior: Concepts, Controversies, Applications, Toronto: Pearson Education Canada Inc., 1995.

Rogers, E. M. Diffusion of Innovations ( $4^{\text {th }}$ ed.), New York: The Free Press, 1995.

Romm, C. T., Pliskin, N., Weber, Y., and Lee, A. "Identifying Organizational Culture Clash in MIS Implementation: When Is it Worth the Effort," Information \& Management (21), 1991, pp. 99-109. 
Schein, E. H. "Coming to a New Awareness of Organizational Culture," Sloan Management Review (25:2), 1984, pp. 3-16.

Tornatzky, L. G., and Klein, K. J. "Innovation Characteristics and Innovation AdoptionImplementation: A Meta-Analysis of Findings," IEEE Transactions on Engineering Management (EM-29:1), February 1982, pp. 28-45.

Walsham, G. Interpreting Information Systems in Organizations, Chichester, UK: John Wiley \& Sons, 1993.

Zammuto, R. F., and O'Connor, E. J. 'Gaining Advanced Manufacturing Technologies' Benefits: The Roles of Organization Design and Culture," Academy of Management Review (17:4), 1992, pp. 701-728.

\section{About the Authors}

Deborah Bunker is a senior lecturer and associate head of school at the School of Information Systems, Technology and Management at the University of New South Wales. She holds a Ph.D. in Information Systems Management. Her research interests are in IS philosophy, IS management, IS diffusion and e-commerce/e-business. She has widely published in these areas. Deborah is a founding member and the secretary of IFIP TC 8 WG 8.6 on the adoption and diffusion of IT. Deborah can be reached by e-mail at d.bunker@unsw.edu.au.

Karlheinz Kautz is professor in systems development and software engineering at the Department for Informatics at the Copenhagen Business School. He holds a Ph.D. in systems development. His research interests are in the diffusion and adoption of information technology innovations, evolutionary systems development, and system development methodologies for advanced application areas, the organizational impact of IT, knowledge management, and software quality and process improvement. He has widely published in these areas. Karl is a founding member and the chairman of the IFIP TC 8 WG 8.6 on the adoption and diffusion of IT. Karlheinz can be reached by e-mail at khk.inf@cbs.edu.

Anne Luu Thanh Nguyen has been a student for the degree of Business Information Technology (Honours) at the University of New South Wales and has been a research assistant for the project, which builds the basis for the research described here. 